\title{
De-Escalating Axillary Surgery in Node-Positive Breast Cancer Treated with Neoadjuvant Systemic Therapy
}

\author{
Sabine R. de Wild ${ }^{a}$ b Janine M. Simons ${ }^{c}$ Marie-Jeanne T.F.D. Vrancken Peeters ${ }^{d, e}$ \\ Marjolein L. Smidt ${ }^{a}$ b Linetta B. Koppert ${ }^{f}$ \\ ${ }^{a}$ Department of Surgery, Maastricht University Medical Centre+, Maastricht, The Netherlands; ${ }^{b}$ GROW, School \\ for Oncology and Developmental Biology, Maastricht University Medical Centre+, Maastricht, The Netherlands; \\ 'Department of Radiotherapy, Erasmus Medical Centre, Rotterdam, The Netherlands; ${ }^{\mathrm{d}}$ Department of Surgery, \\ Netherlands Cancer Institute, Amsterdam, The Netherlands; 'Department of Surgery, Amsterdam University Medical \\ Centre, Amsterdam, The Netherlands; fDepartment of Surgery, Erasmus Medical Centre, Rotterdam, The Netherlands
}

\section{Keywords}

Node-positive breast cancer · Neoadjuvant systemic therapy · Axillary surgery to select patients who may benefit from treatment de-escalation, but also to select patients who may benefit from treatment escalation.

(c) 2021 The Author(s). Published by S. Karger AG, Basel

\begin{abstract}
Background: There is a trend towards de-escalating axillary staging and treatment in breast cancer patients. On account of neoadjuvant systemic therapy, node-positive breast cancer patients can achieve a pathological complete response of the axilla. It is hypothesized that these patients do not benefit from an axillary lymph node dissection (ALND), and thus may be spared the risk of severe post-surgical morbidity. In an effort to omit standard ALND, less invasive axillary staging procedures are being implemented to establish response-guided treatment. However, it is unclear which less invasive staging procedure is most accurate, and long-term data are missing with regard to their oncologic safety. Summary: This article provides an overview of the literature on currently used less invasive axillary staging procedures, the accuracy and feasibility of these procedures in clinical practice, important issues concerning axillary treatment, and issues to be addressed in ongoing or future studies. Key messages: More evidence is needed regarding the safety of replacing standard ALND by less invasive axillary staging procedures in terms of long-term prognosis. These less invasive staging procedures not only serve
\end{abstract}

\section{Introduction}

Since the 1990s, there has been a trend towards less invasive staging and treatment strategies of the axilla in breast cancer patients. The axillary lymph node dissection (ALND), which is associated with the risk of severe post-surgical morbidity such as lymphedema and paraesthesia $[1,2]$, is no longer standard of care in node-negative breast cancer (cN0) patients. On account of important trials such as NSABP B-32, the sentinel lymph node biopsy (SLNB) has replaced standard ALND, based on a comparable survival and regional control, and less morbidity [3-5]. Even if the SLNB is positive (with a maximum of two positive nodes), ALND can be safely omitted in patients who receive breast-conserving therapy and adjuvant treatment [6-10]. It is therefore questioned if performing an SLNB is of added value in these patients. As a result, trials such as INSEMA (NCT02466737), SOUND, and BOOG 2013-08 are currently investigating whether SLNB can be safely omitted in $\mathrm{CN} 0$ patients who are treated with breast-conserving therapy $[11,12]$.
(C) 2021 The Author(s)

Published by S. Karger AG, Basel

This is an Open Access article licensed under the Creative Common Attribution-NonCommercial-4.0 International License (CC BY-NC) (http://www.karger.com/Services/OpenAccessLicense), applicable to the online version of the article only. Usage and distribution for commercial purposes requires written permission.
Correspondence to:

Sabine R.de Wild, s.dewild@ maastrichtuniversity.nl 
In node-positive breast cancer $(\mathrm{cN}+)$ patients, attempts to de-escalate axillary staging and treatment are also made, yet in a less progressive manner. Neoadjuvant systemic therapy (NST) is increasingly used in these patients, which enables assessment of in vivo response to systemic therapy, and has the benefit of downsizing the primary tumour, thereby making breast-conserving therapy more often feasible $[13,14]$. NST can also downsize axillary disease and result in a pathological complete response of the axilla (i.e., axillary-pCR). Axillary-pCR rates vary depending on breast cancer molecular subtype and can be as high as 74\% in HER2-positive patients [15-19]. Patients who achieve an axillarypCR are not expected to benefit from ALND. On that account, less invasive axillary staging procedures have been introduced in an effort to establish response-guided treatment, thereby omitting ALND in case of an axillary-pCR. However, it is unclear whether it is safe to omit standard ALND in cN+ patients treated with NST, with regard to long-term prognosis. A lack of consensus concerning regional management in these patients has resulted in a large variety of axillary staging and treatment strategies worldwide.

\section{Currently Known Less Invasive Axillary Staging Procedures}

In order to replace standard ALND, a less invasive axillary staging procedure has to be highly accurate. In other words, the chance that axillary residual disease is missed should be as low as possible (i.e., low false-negative rate $[\mathrm{FNR}]$ and high negative predictive value [NPV]). The SLNB was the first procedure to be suggested for less invasive axillary staging that could potentially lead to omitting standard ALND in $\mathrm{cN}+$ patients treated with NST. Trials such as SN FNAC, SENTINA, and ACOSOG Z1071 have shown that the SLNB has unacceptable FNRs and a NPV that does not exceed $86 \%$, indicating that residual disease is missed in 1 of 6 patients with a negative SLNB [17, 20-23]. Suggested methods to improve the FNR are the use of immunohistochemistry, dual tracer, and excision of at least 3 SLNs. Even though the latter did have a statistically significant effect on the FNR in a meta-analysis [17], in clinical practice it is often not feasible to remove 3 SLNs. Hence, although successful in cN0 patients, SLNB is not accurate enough as stand-alone procedure in $\mathrm{cN}+$ patients who are treated with NST, possibly because NST and axillary metastases result in an altered lymph drainage. In 2010, the MARI-procedure was introduced, in which an axillary lymph node metastasis was marked with a radioactive iodine seed before NST, and excised after NST with the use of a gamma probe $[24,25]$. This strat- egy overcomes the issue of potentially altered lymph drainage. Although an FNR of 7\% was achieved, its NPV was comparable to that of the SLNB. The definition of axillary-pCR varied between these studies (i.e., counting isolated tumour cells as either negative or positive), which should be kept in mind when comparing their results. A promising alternative is combining SLNB and excision of a marked positive axillary lymph node (i.e., Targeted Axillary Dissection, TAD). Even though the evidence is limited to a few small cohort studies [26-29], it is plausible that a higher accuracy is achieved when these strategies are combined, since the marked lymph node appears not to be the SLN in $23.0-35.2 \%$ of cases $[26,28,29]$. Preliminary results of the RISAS trial (i.e., combining SLNB and MARI-procedure) seem to verify the accuracy of TAD in a multicentre cohort of $227 \mathrm{pa}-$ tients [30]. Final results of the RISAS trial and GANEA-3 (NCT03630913) will have to be awaited to decide which staging procedure is most accurate [31]. In the meantime, other factors are being explored in an effort to further optimize TAD, in particular the type of marker used and the most appropriate timing for marker placement, which both will be discussed below.

\section{Targeted Axillary Dissection: Markers}

Given the idea that a combination procedure is most accurate for axillary staging after NST, and radioactive iodine seeds are not allowed to be used for this purpose in various countries, several variations of TAD have been investigated. Mostly in small and retrospective cohorts, markers such as wire [32-34], carbon ink [3538], magnetic seeds [39, 40], and clips [29] have been used, which all have certain benefits and downsides with regard to identifying the marked lymph node. Wire, carbon ink, and clips are non-radioactive and less expensive than radioactive iodine and magnetic seeds, and therefore often preferred options for TAD. However, a wire needs to be placed just prior to surgery, which can result in planning difficulties, and it can cause discomfort since patients have to keep their arm in a certain position to prevent the wire from dislocating, which is another risk of this procedure. Carbon ink can spread beyond the marked lymph node, which can result in unnecessary removal of more lymph nodes, thus increasing the risk of post-surgical morbidity. Apart from this, clips are not always easily localized with ultrasound, which may indicate the need for a mammography or computed tomography scan. All these drawbacks can result in the inability to perform TAD. The magnetic seed is more or less comparable to the radioactive iodine seed, since a probe (e.g., Sentimag) is used to localize the marked lymph node. Yet, 
the magnetic seed can give an artefact on the magnetic resonance imaging, which may complicate the assessment of response to NST. In a currently recruiting, multicentre, prospective registry study (NCT04580251), the magnetic seed, radioactive iodine seed, and carbon ink are compared with regard to reliability of the individual markers. Outcomes such as marker migration, the ability to localize the marker, and the success rate of excision of the marked lymph node are assessed. The study is expected to be completed in 2023. Other factors that future research should focus on regarding identifying the most optimal marker are patient satisfaction and cost-effectiveness.

\section{Targeted Axillary Dissection: Timing}

Timing also varies amongst different TAD procedures, as it can either be applied as a one-step procedure or a two-step procedure. In a one-step procedure, the metastatic lymph node is marked with a definitive marker (e.g., radioactive iodine seed in the MARI-procedure) before NST, and is identified and excised at the time of surgery. In a two-step procedure, the metastatic lymph node is clipped before NST, and only after NST a definitive marker is placed adjacent to the clip, to enable identification and excision of the clipped lymph node at the time of surgery. It can be considered that a two-step procedure is more prone to fail, and moreover, patients have to undergo an additional procedure. In a study by Nguyen et al. [41], placement of a radioactive iodine seed in the clipped node was possible in only $80 \%$ of the patients. Hartmann et al. [34] also reported a failure rate of $20 \%$ for localizing the clipped node in a study in which wire-placement was attempted. In the recently published multicentre Senta trial, wire-placement in the clipped node was not successful in $22 \%$ of the patients [28]. In almost half of the cases, this was due to the fact that the clipped node could not be identified on ultrasound. The procedure seemed to be associated with a learning curve, since failure rates were less in more experienced participating centres. In the ILINA trial, the additional procedure was omitted, and intra-operative ultrasound was used to guide excision of the clipped node, which had a high success rate [29]. Another method to overcome the need for an additional procedure after NST is currently being investigated in the Magellan trial (NCT03796559). In this trial, a magnetic seed is placed prior to NST instead of after NST. Since the different TAD procedures were mostly explored in small and retrospective cohorts, and not directly compared within a trial, evidence is lacking to determine the most optimal TAD procedure for establishing response-guided treatment.

\section{Response-Guided Axillary Treatment and Long-Term Prognosis}

Response to NST is a strong prognostic indicator, with pCR being associated with improved survival [42, 43]. Patients who achieve a pCR of the breast as well as the axilla have the most favourable prognosis, but also patients with breast-only or axilla-only pCR have improved prognosis [44]. Several studies reported that axillary-pCR seems to have a greater effect on prognosis than breastpCR $[44,45]$. These findings are the major driver of developing response-guided treatment approaches. Less invasive axillary staging procedures were initially proposed to omit unnecessary ALND in patients with axillary-pCR. However, it does not only enable omission of ALND in selected patients, it also serves as a procedure to identify patients who may benefit from additional treatment. In case of residual disease, selected patients may benefit from ALND and/or regional radiotherapy. Almahariq et al. [46] conducted a retrospective study to assess whether the extent of axillary surgery affected prognosis in cT1$3 \mathrm{~N} 1$ patients with residual disease in $1-3$ lymph nodes who were treated with regional radiotherapy. In a matched cohort, 304 patients who only underwent SLNB had significantly lower survival than the 1,313 patients who underwent ALND, with estimated 5-year overall survival rates of 71 and $77 \%$, respectively $(p=0.006)$. In a subgroup of luminal A or B tumours with residual disease in a single lymph node, SLND and ALND were associated with similar overall survival rates of 85 and $82 \%$, respectively. In a retrospective study by Laot et al. [47], it was suggested that depending on breast cancer molecular subtype, the extent of residual axillary disease may affect prognosis in a different manner. Prognosis was similar for patients with residual disease in up to 3 lymph nodes and patients with axillary-pCR in case of luminal breast cancer, whereas residual disease in 4 or more lymph nodes was associated with decreased prognosis. In patients with HER2+ or triple-negative (TN) breast cancer, prognosis was not only decreased in patients with 4 or more positive lymph nodes but also in patients with 1-3 positive lymph nodes [47]. Apart from additional regional treatment, patients with residual disease can also benefit from additional systemic treatment such as TDM-1 in HER2+ patients and capecitabine in TN patients, as was demonstrated in the Katherine and Create- $X$ trials, respectively $[48,49]$. Residual disease may be limited to the axilla; therefore, it is of utmost importance to accurately identify axillary disease to provide patients with the appropriate adjuvant treatment.

Several ongoing trials are assessing the value of adjuvant ALND and/or regional radiotherapy in $\mathrm{cN}+$ patients treated with NST. The NSABP-B51/RTOG 1304 and ATNEC trials include patients with axillary-pCR 
(NCT01872975, NCT04109079), the Alliance A011202 and TAXIS trials include patients with residual disease (NCT01901094, NCT03513614), and the MINIMAX registry study includes both patients with an axillary-pCR and those with residual disease (NCT04486495). Furthermore, the 3-year follow-up results of response-guided axillary treatment according to the MARI protocol [50] (i.e., use of PET-CT as pre-NST staging, followed by the MARI procedure as post-NST staging) in a cohort of $272 \mathrm{pa}-$ tients were presented at EBCC 2020 [51].

\section{Conclusion}

In $\mathrm{cN}+$ patients who are treated with NST, there is an undesired large variety in axillary staging and treatment strategies worldwide. TAD seems to be most accurate for axillary staging in $\mathrm{cN}+$ patients who are treated with NST. While the results of validation trials are awaited, more evidence is needed regarding the safety of replacing standard ALND by less invasive axillary staging in terms of long-term prognosis. Moreover, clinicians should keep in mind that less invasive axillary staging procedures not only serve to select patients who may benefit from treatment de-escalation, but also to select patients who may benefit from treatment escalation.

\section{Conflict of Interest Statement}

The authors have no conflicts of interest to declare.

\section{Funding Sources}

This study did not receive any funding.

\section{Author Contributions}

S.d.W. prepared the manuscript and is the corresponding author. J.S. prepared the manuscript. M.V.P. and M.S. are members of the writing committee. L.K. supervised S.d.W. and J.S. All authors have contributed to the study's conception and design, and have read and edited the manuscript. All authors approved the final manuscript.

\section{References}

1 Lucci, A, McCall LM, Beitsch PD, Whitworth PW, Reintgen DS, Blumencranz PW, et al. Surgical complications associated with sentinel lymph node dissection (SLND) plus axillary lymph node dissection compared with SLND alone in the American College of Surgeons Oncology Group Trial Z0011. J Clin Oncol, 2007. 25(24): p. 3657-63.

2 Mansel RE, Fallowfield L, Kissin M, Goyal A, Newcombe RG, Dixon JM, et al. Randomized multicenter trial of sentinel node biopsy versus standard axillary treatment in operable breast cancer: the ALMANAC Trial. J Natl Cancer Inst. 2006;98(9):599609.

3 Ashikaga T, Krag DN, Land SR, Julian TB, Anderson SJ, Brown AM, et al. Morbidity results from the NSABP B-32 trial comparing sentinel lymph node dissection versus axillary dissection. J Surg Oncol. 2010; 102(2):111-8.

4 Krag DN, Anderson SJ, Julian TB, Brown AM, Harlow SP, Ashikaga T, et al. Technical outcomes of sentinel-lymph-node resection and conventional axillary-lymphnode dissection in patients with clinically node-negative breast cancer: results from the NSABP B-32 randomised phase III trial. Lancet Oncol. 2007;8(10):881-8.

5 Krag DN, Anderson SJ, Julian TB, Brown AM, Harlow SP, Costantino JP, et al. Sentinel-lymph-node resection compared with conventional axillary-lymph-node dissection in clinically node-negative patients with breast cancer: overall survival findings from the NSABP B-32 randomised phase 3 trial. Lancet Oncol. 2010;11(10):927-33.
6 Donker M, van Tienhoven G, Straver ME, Meijnen P, van de Velde CJ, Mansel RE, et al. Radiotherapy or surgery of the axilla after a positive sentinel node in breast cancer (EORTC 10981-22023 AMAROS): a randomised, multicentre, open-label, phase 3 non-inferiority trial. Lancet Oncol. 2014; 15(12):1303-10.

7 Galimberti V, Cole BF, Viale G, Veronesi P, Vicini E, Intra M, et al. Axillary dissection versus no axillary dissection in patients with breast cancer and sentinel-node micrometastases (IBCSG 23-01): 10-year follow-up of a randomised, controlled phase 3 trial. Lancet Oncol. 2018;19(10):1385-93.

8 Galimberti V, Cole BF, Zurrida S, Viale G, Luini A, Veronesi P, et al. Axillary dissection versus no axillary dissection in patients with sentinel-node micrometastases (IBCSG 23-01): a phase 3 randomised controlled trial. Lancet Oncol. 2013;14(4): 297-305.

9 Giuliano AE, Ballman KV, McCall L, Beitsch PD, Brennan MB, Kelemen PR, et al. Effect of Axillary Dissection vs No Axillary Dissection on 10-Year Overall Survival Among Women With Invasive Breast Cancer and Sentinel Node Metastasis: The ACOSOG Z0011 (Alliance) Randomized Clinical Trial. JAMA. 2017;318(10):91826.

10 Giuliano AE, McCall L, Beitsch P, Whitworth PW, Blumencranz P, Leitch AM, et al. Locoregional recurrence after sentinel lymph node dissection with or without axillary dissection in patients with sentinel lymph node metastases: the American College of Surgeons Oncology Group Z0011 randomized trial. Ann Surg. 2010;252(3): 426-3; discussion 432-3.

11 van Roozendaal LM, Vane MLG, van Dalen T, van der Hage JA, Strobbe LJA, Boersma LJ, et al. Clinically node negative breast cancer patients undergoing breast conserving therapy, sentinel lymph node procedure versus follow-up: a Dutch randomized controlled multicentre trial (BOOG 2013-08). BMC Cancer. 2017; 17(1):459.

12 Gentilini O, Veronesi U. Abandoning sentinel lymph node biopsy in early breast cancer? A new trial in progress at the European Institute of Oncology of Milan (SOUND: Sentinel node vs Observation after axillary UltraSouND). Breast. 2012;21(5):678-81.

13 Fisher B, Bryant J, Wolmark N, Mamounas E, Brown A, Fisher ER, et al. Effect of preoperative chemotherapy on the outcome of women with operable breast cancer. J Clin Oncol. 1998;16(8):2672-85.

14 van der Hage JA, van de Velde CJ, Julien JP, Tubiana-Hulin M, Vandervelden C, Duchateau L. Preoperative chemotherapy in primary operable breast cancer: results from the European Organization for $\mathrm{Re}$ search and Treatment of Cancer trial 10902. J Clin Oncol. 2001;19(22):4224-37.

15 Boughey JC, McCall LM, Ballman KV, Mittendorf EA, Ahrendt GM, Wilke LG, et al. Tumor biology correlates with rates of breast-conserving surgery and pathologic complete response after neoadjuvant chemotherapy for breast cancer: findings from the ACOSOG Z1071 (Alliance) Prospective Multicenter Clinical Trial. Ann Surg. 2014; 260(4):608-6; discussion 614-6. 
16 Dominici LS, Negron Gonzalez VM, Buzdar AU, Lucci A, Mittendorf EA, Le-Petross $\mathrm{HT}$, et al. Cytologically proven axillary lymph node metastases are eradicated in patients receiving preoperative chemotherapy with concurrent trastuzumab for HER2-positive breast cancer. Cancer. 2010; 116(12):2884-9

17 Simons JM, van Nijnatten TJA, van der Pol CC, Luiten EJT, Koppert LB, Smidt ML. Diagnostic Accuracy of Different Surgical Procedures for Axillary Staging After Neoadjuvant Systemic Therapy in Node-positive Breast Cancer: A Systematic Review and Meta-analysis. Ann Surg. 2019;269(3): 432-42.

18 Zetterlund L, Celebioglu F, Hatschek T, Frisell J, de Boniface J. Long-term prognosis is associated with residual disease after neoadjuvant systemic therapy but not with initial nodal status. Br J Surg. 2020.

19 Samiei S, Simons JM, Engelen SME, BeetsTan RGH, Classe JM, Smidt ML. Axillary Pathologic Complete Response After Neoadjuvant Systemic Therapy by Breast Cancer Subtype in Patients With Initially Clinically Node-Positive Disease: A Systematic Review and Meta-analysis. JAMA Surg. 2021;156(6):e210891.

20 Tee SR, Devane LA, Evoy D, Rothwell J, Geraghty J, Prichard RS, et al. Meta-analysis of sentinel lymph node biopsy after neoadjuvant chemotherapy in patients with initial biopsy-proven node-positive breast cancer. Br J Surg. 2018;105(12):1541-52.

21 Boileau JF, Poirier B, Basik M, Holloway CM, Gaboury L, Sideris L, et al. Sentinel node biopsy after neoadjuvant chemotherapy in biopsy-proven node-positive breast cancer: the SN FNAC study. J Clin Oncol. 2015;33(3):258-64.

22 Boughey JC, Suman VJ, Mittendorf EA, Ahrendt GM, Wilke LG, Taback B, et al. Sentinel lymph node surgery after neoadjuvant chemotherapy in patients with nodepositive breast cancer: the ACOSOG Z1071 (Alliance) clinical trial. JAMA. 2013; 310(14):1455-61.

23 Kuehn T, Bauerfeind I, Fehm T, Fleige B, Hausschild M, Helms G, et al. Sentinellymph-node biopsy in patients with breast cancer before and after neoadjuvant chemotherapy (SENTINA): a prospective, multicentre cohort study. Lancet Oncol. 2013;14(7):609-18.

24 Straver ME, Loo CE, Alderliesten T, Rutgers EJ, Vrancken Peeters MT. Marking the axilla with radioactive iodine seeds (MARI procedure) may reduce the need for axillary dissection after neoadjuvant chemotherapy for breast cancer. Br J Surg. 2010; 97(8):1226-31.

25 Donker M, Straver ME, Wesseling J, Loo CE, Schot M, Drukker CA, et al. Marking axillary lymph nodes with radioactive iodine seeds for axillary staging after neoadjuvant systemic treatment in breast cancer patients: the MARI procedure. Ann Surg. 2015;261(2):378-82.
26 Caudle AS, Yang WT, Krishnamurthy S, Mittendorf EA, Black DM, Gilcrease MZ, et al. Improved Axillary Evaluation Following Neoadjuvant Therapy for Patients With Node-Positive Breast Cancer Using Selective Evaluation of Clipped Nodes: Implementation of Targeted Axillary Dissection. J Clin Oncol. 2016;34(10):1072-8.

27 Caudle AS, Yang WT, Mittendorf EA, Black DM, Hwang R, Hobbs B, et al. Selective surgical localization of axillary lymph nodes containing metastases in patients with breast cancer: a prospective feasibility trial. JAMA Surg. 2015;150(2):137-43.

28 Kuemmel S, Heil J, Rueland A, Seiberling C, Harrach H, Schindowski D, et al. A Prospective, Multicenter Registry Study to Evaluate the Clinical Feasibility of Targeted Axillary Dissection (TAD) in Node-Positive Breast Cancer Patients. Ann Surg. 2020 Nov 4. doi: 10.1097/ SLA.0000000000004572.

29 Siso C, de Torres J, Esgueva-Colmenarejo A, Espinosa-Bravo M, Rus N, Cordoba O, et al. Intraoperative Ultrasound-Guided Excision of Axillary Clip in Patients with Node-Positive Breast Cancer Treated with Neoadjuvant Therapy (ILINA Trial): A New Tool to Guide the Excision of the Clipped Node After Neoadjuvant Treatment. Ann Surg Oncol. 2018;25(3):784-91.

30 Simons J, JA v Nijnatten T, Koppert LB, van der Pol CC, v Diest PJ, Jager A, et al. Abstract GS1-10: Radioactive Iodine Seed placement in the Axilla with Sentinel lymph node biopsy after neoadjuvant chemotherapy in breast cancer: Results of the prospective multicenter RISAS trial. Cancer Res. 2021;81(4 Suppl):GS1-10-GS1-10.

31 van Nijnatten TJA, Simons JM, Smidt ML, van der Pol CC, van Diest PJ, Jager A, et al. A Novel Less-invasive Approach for Axillary Staging After Neoadjuvant Chemotherapy in Patients With Axillary Nodepositive Breast Cancer by Combining Radioactive Iodine Seed Localization in the Axilla With the Sentinel Node Procedure (RISAS): A Dutch Prospective Multicenter Validation Study. Clin Breast Cancer. 2017; 17(5):399-402.

32 Balasubramanian R, Morgan C, Shaari E, Kovacs T, Pinder SE, Hamed H, et al. Wire guided localisation for targeted axillary node dissection is accurate in axillary staging in node positive breast cancer following neoadjuvant chemotherapy. Eur J Surg Oncol. 2020;46(6):1028-33.

33 Dashevsky BZ, Altman A, Abe H, Jaskowiak N, Bao J, Schacht DV, et al. Lymph node wire localization post-chemotherapy: Towards improving the false negative sentinel lymph node biopsy rate in breast cancer patients. Clin Imaging. 2018;48:69-73.

34 Hartmann S, Reimer T, Gerber B, Stubert J, Stengel B, Stachs A. Wire localization of clip-marked axillary lymph nodes in breast cancer patients treated with primary systemic therapy. Eur J Surg Oncol. 2018; 44(9):1307-11.
35 Patel R, MacKerricher W, Tsai J, Choy N, Lipson J, Ikeda D, et al. Pretreatment Tattoo Marking of Suspicious Axillary Lymph Nodes: Reliability and Correlation with Sentinel Lymph Node. Ann Surg Oncol. 2019;26(8):2452-8.

36 Natsiopoulos I, Intzes S, Liappis T, Zarampoukas K, Zarampoukas T, Zacharopoulou $\mathrm{V}$, et al. Axillary Lymph Node Tattooing and Targeted Axillary Dissection in Breast Cancer Patients Who Presented as $\mathrm{cN}+\mathrm{Be}$ fore Neoadjuvant Chemotherapy and $\mathrm{Be}$ came cN0 After Treatment. Clin Breast Cancer. 2019;19(3):208-15.

37 Allweis TM, Menes T, Rotbart N, Rapson Y, Cernik H, Bokov I, et al. Ultrasound guided tattooing of axillary lymph nodes in breast cancer patients prior to neoadjuvant therapy, and identification of tattooed nodes at the time of surgery. Eur J Surg Oncol. 2020;46(6): 1041-5.

38 Kim WH, Kim HJ, Kim SH, Jung JH, Park HY, Lee J, et al. Ultrasound-guided duallocalization for axillary nodes before and after neoadjuvant chemotherapy with clip and activated charcoal in breast cancer patients: a feasibility study. BMC Cancer. 2019;19(1):859.

39 Mariscal Martínez A, Vives Roselló I, Salazar Gómez A, Catanese A, Pérez Molina M, Solà Suarez M, et al. Advantages of preoperative localization and surgical resection of metastatic axillary lymph nodes using magnetic seeds after neoadjuvant chemotherapy in breast cancer. Surg Oncol. 2021; $36: 28-33$.

40 Taback B, Jadeja P, Ha R. Enhanced Axillary Evaluation Using Reflector-Guided Sentinel Lymph Node Biopsy: A Prospective Feasibility Study and Comparison With Conventional Lymphatic Mapping Techniques. Clin Breast Cancer. 2018; 18(5):e869-74.

41 Nguyen TT, Hieken TJ, Glazebrook KN, Boughey JC. Localizing the Clipped Node in Patients with Node-Positive Breast Cancer Treated with Neoadjuvant Chemotherapy: Early Learning Experience and Challenges. Ann Surg Oncol. 2017;24(10): 3011-6.

42 Cortazar P, Zhang L, Untch M, Mehta K, Costantino JP, Wolmark N, et al. Pathological complete response and long-term clinical benefit in breast cancer: the CTNeoBC pooled analysis. Lancet. 2014;384(9938): 164-72.

43 von Minckwitz G, Untch M, Blohmer JU, Costa SD, Eidtmann H, Fasching PA, et al. Definition and impact of pathologic complete response on prognosis after neoadjuvant chemotherapy in various intrinsic breast cancer subtypes. J Clin Oncol. 2012; 30(15):1796-804.

44 Mougalian SS, Hernandez M, Lei X, Lynch S, Kuerer HM, Symmans WF, et al. TenYear Outcomes of Patients With Breast Cancer With Cytologically Confirmed Axillary Lymph Node Metastases and Pathologic Complete Response After Primary Systemic Chemotherapy. JAMA Oncol. 2016;2(4):508-16. 
45 Fayanju OM, Ren Y, Thomas SM, Greenup RA, Plichta JK, Rosenberger LH, et al. The Clinical Significance of Breast-only and Node-only Pathologic Complete Response (pCR) After Neoadjuvant Chemotherapy (NACT): A Review of 20,000 Breast Cancer Patients in the National Cancer Data Base (NCDB). Ann Surg. 2018;268(4):591-601.

46 Almahariq MF, Levitin R, Quinn TJ, Chen PY, Dekhne N, Kiran S, et al. Omission of Axillary Lymph Node Dissection is Associated with Inferior Survival in Breast Cancer Patients with Residual N1 Nodal Disease Following Neoadjuvant Chemotherapy. Ann Surg Oncol. 2021;28(2):930-40.
47 Laot L, Laas E, Girard N, Dumas E, Daoud E, Grandal B, et al. The Prognostic Value of Lymph Node Involvement after Neoadjuvant Chemotherapy Is Different among Breast Cancer Subtypes. Cancers (Basel). 2021;13(2): 171 .

48 Masuda N, Lee SJ, Ohtani S, Im YH, Lee ES, Yokota I, et al. Adjuvant Capecitabine for Breast Cancer after Preoperative Chemotherapy. N Engl J Med. 2017;376(22):214759.

49 von Minckwitz G, Huang CS, Mano MS, Loibl S, Mamounas EP, Untch $\mathrm{M}$, et al. Trastuzumab Emtansine for Residual Invasive HER2-Positive Breast Cancer. N Engl J Med. 2019;380(7):617-28.
50 van der Noordaa MEM, van Duijnhoven FH, Straver ME, Groen EJ, Stokkel M, Loo $\mathrm{CE}$, et al. Major Reduction in Axillary Lymph Node Dissections After Neoadjuvant Systemic Therapy for Node-Positive Breast Cancer by combining PET/CT and the MARI Procedure. Ann Surg Oncol. 2018;25(6):1512-20.

51 van Loevezijn A, van der Noordaa MEM, van Duijnhoven F, Groen EJ, Stokkel MPM, Loo CE, et al. Tailored axillary treatment after neoadjuvant systemic therapy in clinically node-positive breast cancer patients is safe: 3-year follow-up of the MARI protocol. Eur J Cancer. 2020;138:S3-4. 